\title{
O USO DA HERMENÊUTICA DOS PRECEDENTES JUDICIAIS PELOS TRIBUNAIS SUPERIORES COMO TÉCNICA DECISÓRIA SIMÉTRICA ÀS SENTENÇAS NORMATIVAS: POR UM EQUILÍBRIO JURISPRUDENCIAL NO DIREITO
}

\section{THE USE OF THE HERMENEUTICS OF JUDICIAL PRECEDENTS BY THE SUPERIOR COURTS AS A TECHNIQUE OF A SIMMETRIC DECISION TO THE JUDICIAL NORMATIVE SENTENCES: BY A JURISPRUDENTIAL BALANCE OF LAW}

\author{
Cândice Lisboa Alves ${ }^{1}$ \\ Gustavo Nascimento Tavares ${ }^{2}$ \\ Nathalia Ayres Cestari ${ }^{3}$
}

RESUMO: O presente artigo propõe, discutir a aplicação da hermenêutica dos precedentes judiciais pelas cortes superiores como técnica decisória de contenção frente à técnica das sentenças normativas que exercem um papel de impulso criativo na interpretação jurídica. Nesse sentido, utilizando-se da metodologia indutiva, o trabalho visa erguer um juízo de probabilidade, demonstrando que existe uma simetria entre a utilização das duas técnicas, fundado na possibilidade de aplicação da hermenêutica dos precedentes no direito brasileiro e no reconhecimento, e posterior delimitação, do uso das sentenças normativas, justificar-se-á tais proposições com fundamentos principiológicos constitucionais, processuais e estudo comparativo de decisões judiciais. Destarte, as cortes superiores podem adotar o preceito de seguir seus próprios precedentes, como forma de exercer um controle interno das decisões judiciais limitando o potencial criativo conquistado pelo papel

\footnotetext{
${ }^{1}$ Bacharel em Direito, (1999-2004) pela Universidade Federal de Viçosa, Mestre em Direito (20042006) pela Universidade Federal de Viçosa, Doutora em Direito Público pela PUC Minas (20092013); vinculo institucional e profissional pela Universidade Federal de Uberlândia, na função de Professora Adjunta. E-mail: candicelisboa.prof@gmail.com. ORCID: https://orcid.org/0000-00030514-5025.

${ }^{2}$ Bacharel em Direito, (2011-2015) pela Universidade Federal de Uberlândia - UFU e Mestrando em Direito pela Universidade Federal de Uberlândia - UFU, Programa de Pós Graduação em Direito, turma 2016-2017. E-mail: gustavosersan@gmail.com. ORCID: https://orcid.org/00000003-3847-9603

${ }^{3}$ Bacharel em Direito, (2012-2017) pela Universidade Federal de Uberlândia e pós-graduada em Direito Eleitoral, (2018-2020) pela Faculdade Ibmec São Paulo. E-mail: nathaliacestari@ hotmail.com. ORCID: https://orcid.org/0000-0002-9610-6269
} 
normativo das cortes. Portanto, o equilíbrio entre técnicas decisórias utilizadas pelas cortes superiores promove harmonia entre segurança jurídica e justiça no direito.

Palavras-chave: Sentenças Normativas; Hermenêutica dos precedentes judiciais; Técnicas decisórias.

ABSTRACT: The present article proposes to discuss the application of the hermeneutics of judicial precedents by the superior courts as a decision - making technique of contention in relation to the technique of normative sentences that play a creative impulse role in juridical interpretation. In this sense, using the inductive methodology, the work aims to raise a probability judgment, demonstrating that there is a symmetry between the use of both techniques, based on the possibility of applying the hermeneutics of precedent in Brazilian law and recognition, and later delimitation, Of the use of normative sentences, such propositions will be justified with constitutional principles, constitutional, procedural and comparative study of judicial decisions. Hence, higher courts can adopt the precept of following their own precedents, as a way of exercising internal control over judicial decisions, limiting the creative potential gained by the normative role of courts. Therefore, the balance between decision-making techniques used by the higher courts promotes harmony between legal certainty and justice in law.

Key-words: Normative sentences; Hermeneutics of judicial precedents; Decision making techniques.

Sumário: 1. Introdução; 2. A hermenêutica dos precedentes aplicada às decisões judiciais das cortes superiores; 3 . A superação do paradigma de legislador negativo e a atuação normativa das cortes superiores por meio das sentenças normativas; 4. A hermenêutica dos precedentes judiciais como contraponto ao uso das técnicas decisórias das sentenças normativas na jurisdição constitucional e infraconstitucional; 5. A atuação dos atores do STF e do STJ diante da aplicação das duas técnicas decisórias: discussão de casos em que as cortes foram pródigas em produzir normas, mas contidas em fixar limites; 6. Considerações Finais; 7. Referências.

\section{INTRODUÇÃO}

$\mathrm{O}$ presente artigo tem como objetivo justificar a hermenêutica dos precedentes judiciais como um ponto de equilíbrio entre liberdade interpretativadecisória e os preceitos constitucionais de estabilidade e previsibilidade no direito, demonstrando que o respeito das cortes superiores aos próprios precedentes, é necessário para limitar à interpretação no direito. Por opção metodológica será 
abordado os seguintes tribunais superiores, o Superior Tribunal de Justiça (STJ) e o Supremo Tribunal Federal (STF).

Destarte, o tema delimita-se ao estudo das técnicas interpretativas das decisões judiciais, observadas como fontes convergentes e formatadoras do Direito, e colocadas sob o vetor do novo paradigma hermenêutico do direito, para, a partir dessas premissas, extrair uma vinculabilidade das cortes superiores aos próprios precedentes como meio de equilibrar o uso das sentenças normativas. Desse modo, a hipótese é: As cortes superiores podem/devem seguir seus precedentes para alcançar equilíbrio entre a capacidade normativa e a segurança jurídica. Por conseguinte, o objetivo geral consiste em extrair do nosso ordenamento uma aplicação diametralmente complementar entre hermenêutica dos precedentes e sentenças normativas.

Nessa perspectiva, os objetivos específicos são: (i) discutir a aplicação da hermenêutica dos precedentes às decisões judiciais, extraindo um compromisso dos tribunais superiores de observar seus precedentes; (ii) apresentar a evolução da jurisprudência processual que modificou a estrutura das cortes superiores de meros legisladores negativos para cortes de criação normativa por meio de suas sentenças; (iii) demonstrar que e a evolução do uso das técnicas decisórias das sentenças normativas na jurisdição constitucional e infraconstitucional necessita de uma adoção correta da hermenêutica dos precedentes para equilibrar as decisões judiciais das cortes superiores; (iv) por fim, debater os papéis ambíguos das cortes, ou seja, a prodigalidade em relação ao uso das sentenças normativas e o uso comedido e desvinculado da hermenêutica dos precedentes judiciais.

Nessa acepção, para discutir os atributos das decisões judiciais no âmbito dos tribunais superiores, o marco teórico é Ademar Borges de Sousa Filho - Sentenças Aditivas na jurisdição constitucional brasileira, e Luiz Guilherme Marinoni Precedentes Obrigatórios, e também, demais bibliografia sobre direito processual e constitucional, versando sobre técnicas decisórias e hermenêutica dos precedentes. 
Em continuidade, o estado da discussão encontra-se em: deve existir, ou não, a responsabilidade das cortes superiores em observar seus próprios precedentes. Por meio desta perspectiva, o trabalho se propõe a debater o controle das decisões judiciais por meio da utilização simétrica de duas técnicas decisórias, isto é, uma de abertura normativa, e outra de fechamento interpretativo, entretanto ambas com possibilidades de modificação, evolução e ruptura.

Dito isto, para abordar a modelagem de limites à capacidade decisória dos tribunais superiores, será utilizado a metodologia indutiva. Ou seja, a partir de um juízo de probabilidade, de aderência ou não, das teorias propostas à hipótese, buscase chegar ao postulado geral de que, a técnica decisória da hermenêutica dos precedentes pode/deve ser utilizada como meio de contrapor a liberdade criativa dos tribunais pelo uso das sentenças normativas e com isso, trazer estabilidade e equilíbrio ao direito.

\section{A HERMENÊUTICA DOS PRECEDENTES APLICADA ÀS DECISÕES JUDICIAIS DAS CORTES SUPERIORES}

A evolução processual brasileira demonstra uma convergência das jurisdições constitucional e infraconstitucional (ZANETI, 2014, p. 39). O Código de Processo Civil de 2015 é importante ferramenta que busca solidificar esta fusão, por meio do aumento da capacidade decisória dos tribunais, de mecanismos de uniformização das decisões, e principalmente, um modelo normativo de precedentes (vide arts. 10; 926, 927, 489 do CPC/2015) (BRASIL, 2015). Tal modelo se apresenta compatível mesmo em países de matriz do Civil Law4, como o Brasil (MARINONI, 2014, p. 101).

4 Civil Law ou sistema romano-germânico representa a família de direito em que as normas eram codificadas, e a interpretação era originalmente vedada, sendo apenas permitido a aplicação da lei pelos juízes. Em tal sistema iniciado após a revolução francesa, não havia a preocupação do 
Por hermenêutica dos precedentes judiciais entende-se, o modo de interpretar com continuidade as decisões judiciais, levando em conta, a fundamentação específica e nuclear sobre a matéria decidida, e nesse sentido, utilizar-se desta argumentação produzida nas decisões passadas para proferir decisões presentes que se encaixem na mesma categoria de fatos, ou ainda, pautado nessa mesma argumentação, diferenciar ou revogar a aplicação/vinculação das decisões tomadas anteriormente, tendo por base, casos sob judice, desde que se justifique, juridicamente, a revogação/superação (overrruling ${ }^{5}$ ) e a distinção (distinguishing ${ }^{6}$ ).

$\mathrm{O}$ modelo normativo dos precedentes judiciais pode ser visto como, o conjunto de técnicas próprias da teoria do direito, e não apenas de um sistema (tradição) específico(a) de direito, que tem por função estabelecer formas de manipular as decisões judiciais no tempo garantindo que o direito não se torne imutável, mas também conserve sua característica de exercer a jurisdição com igualdade, racionalidade e segurança (MARINONI, 2014, p. 96). Ou seja, é uma técnica que permite que decisões formadas em casos concretos sirvam de complemento normativo para casos futuros, desde que, mantenha relação de equivalência fática entre os casos julgados e os casos futuros. Em síntese, precedentes judiciais aplicados às decisões objetivam dar igualdade na aplicação do direito (ZANETI, 2015, p. 102).

A evolução desta técnica permitiu que os precedentes fossem utilizados com valor vinculante, e não apenas valor persuasivo, porém, como forma de equilibrar a

juiz interpretar a lei, seu papel era apenas aplicador da lei. Esta tradição jurídica passou por mudanças ao longo da história e se adaptou à nova realidade do direito.

5 Overruling é a possibilidade de modificar a interpretação a partir de uma decisão judicial e com isso tornar obsoleto os precedentes sobre o tema, é uma mudança de entendimento que renova a interpretação e passa a valer para casos futuros sobre o mesmo tema.

6 Distinguishing é a técnica dentro da hermenêutica dos precedentes aplicada para casos em que, diante do contexto fático é criado uma decisão paralela ao precedente antes consolidado, de modo que as duas interpretações se mantém no sistema, porém, a decisão que diferencia o caso para não aplicar o precedente, pode, ou não, formar outro precedente, isso irá depender de casos futuros, pois, um precedente completa seu processo hermenêutico quando realiza-se duas premissas, que o são: (i) o momento de sua formação; (ii) o momento de sua aplicação. 
rigidez da vinculabilidade foram desenvolvidas técnicas de superação e distinção dos precedentes para não petrificar a interpretação jurídica (MARINONI, 2014 p. 30).

Tais técnicas de superação (overruling) e de distinção (distinguishing) são mecanismos que permitem que a decisão que se torna precedente possua meios de ser reinterpretada diante de alguma necessidade revisional do entendimento, decorrente de alguma mudança externa, de modo que os critérios de aplicação da distinção e da superação são tomados a partir dos fatos que compõe o caso sob judice, Nesse sentido vale ressaltar (i) a mudança da lei é um fato que constitui um fator relevante para a mudança de um precedente, seja por revogação ou por distinção; (ii) no mesmo sentido, quando juiz está diante de um precedente inconstitucional ${ }^{7}$, ele pode afastá-lo desde que fundamente exaustivamente sua decisão, pois, no Brasil o Judiciário tem a prerrogativa de afastar uma lei inconstitucional, e de forma análoga pode também afastar um precedente. Contudo, o que é totalmente vedado para a aplicação destas modalidades é a discricionariedade do interprete (STRECK, 2016).

Voltando um pouco na história do direito, a hermenêutica dos precedentes tem origem nos países do Common Law8, por meio do instituto do Stare decisis9, como uma tentativa de trazer igualdade na aplicação do direito, e embora estejam estreitamente conectados, os citados conceitos possuem distinções entre

7 Há posições de juristas que entendem que o julgador diante de um precedente inconstitucional deve aplicá-lo com uma ressalva de entedimento em sua decisão, e desta forma abrir a possibilidade da discussão subir de isntância até chegar à corte que fixou o precedente, e assim possa revê-lo, esta a posição dos ditos transcendentalistas, por outro lado, este artigo e seus autores adotam a visão que foi exposta no texto, de que o juíz pode afastar um precedente inconstitucional desde que fundamente, esta é a posição dos hermeneutas.

8 Common Law ou direito anglo-saxão, representa toda uma tradição ou família jurídica que se desenvolveu em certos países (Inglaterra e E.U.A.) e que o direito é revelado por meio das decisões dos tribunais, neste sistema, os juízes não estão vinculados a lei, mas as decisões judiciais das cortes. O instituto do Stare Decisis nasceu deste sistema, assim como a doutrina de precedentes que se modificou ao longo dos anos.

9 Stare decisis é a autoridade que vincula a decisão de um caso paradigma à outros casos sobrepostos na mesma categoria de fatos. Tal expressão tem origem do latim e significa: respeitar o que está decidido e não modificar o que está estabelecido. 
si10(OLIVEIRA, 2014, p.46-48). Nos países originários da tradição do Civil Law, a tentativa foi apostar na diminuição da capacidade interpretativa do juiz, vinculandoo somente à lei (MARINONI, 2016, p. 51).

As transformações sociais com íntimos reflexos na ciência jurídica demonstraram que o método adotado em países do Common Law é mais efetivo em dar segurança jurídica do que a teoria da legalidade estrita, proposta pela tradição do Civil Law (MARINONI, 2016, p. 53), pois em ambas tradições, a interpretação é imprescindível.

Com a modificação do direito nos últimos séculos e a profusão das tecnologias dos dois sistemas, com diversas adaptações, houve, em certos aspectos, uma convergência entre Civil Law e Common Law, ocasionando diversos ordenamentos híbridos, que apesar de serem originalmente filiados há uma tradição, possuem elementos incorporados historicamente proveniente de outra tradição jurídica (ZANETI, 2015, p. 45).

Em síntese, nos países de tradição do Common Law a vinculação do interprete repousa no costume praticado e chancelado pelo Judiciário por meio de suas decisões, já nos países de tradição do Civil Law, o aplicador tem vinculação somente à lei. Porém, com a evolução e continuidade das duas tradições e do próprio direito, o que se viu foi que, em ambos os sistemas a interpretação deve permear as decisões judiciais e diante disso os mecanismos de limites das duas tradições podem coexistir de maneira complementar.

Feito essas considerações, o constitucionalismo pode ser considerado o grande vetor que permite a comunicabilidade dessas duas tradições. No Brasil por exemplo, nossa influência clássica provém do Civil Law, mas, devido à

10 Embora se tenha falado anteriormente na ligação direta entre o sistema da common law com o sistema de precedentes eles não se confundem. Ao se mencionar o sistema da common law, estar-se-á se referindo ao modelo de direito inglês caracterizado por possuir como principal fonte o costume, nascido como forma de oposição ao poder dos feudos pelos Reis ingleses. Já o sistema do stare decisis se refere ao modo de operacionalizar o sistema da common law, conferindo certeza a essa prática. (OLIVEIRA, 2014, p. 46) 
Constituição de 1891 e a inclusão do controle difuso de constitucionalidade baseado no direito norte-americano, a jurisdição constitucional brasileira evolui adotando traços da tradição jurídica do Common Law, principalmente após a Constituição da República Federativa do Brasil (CRFB/1988), quando houve uma explosão da jurisdição constitucional no país. Portanto, o sistema brasileiro pode ser considerado um híbrido entre às duas tradições (ZANETTI, 2015, p. 56).

A jurisdição constitucional foi pioneira no sistema brasileiro em utilizar uma teoria de precedentes nas decisões em controle de constitucionalidade, porém sem uniformização, sem uma aplicação equitativa pelas cortes, e nem fixar graus de vinculabilidade. Com o Código de Processo Civil de 2015, busca-se adotar um modelo normativo de precedentes compatível com nossa ordem jurídica, que seja aplicado em toda a jurisdição, sem deixar de lado a teoria da legalidade, mas apenas utilizando-se dessa técnica hermenêutica para dar maior racionalidade ao nosso sistema (ZANETI, 2015, p. 102).

O modelo de precedentes proposto no Código de Processo é condizente com a prática judicial do país, de forma que tal modelo é complementar ao modelo legalista de utilização da lei como fonte primária. Tal modelo, conforme esculpido no Código de Processo Civil de 2015 (CPC/2015), em certa medida, deixa em aberto a vinculabilidade das próprias cortes em seguir seus precedentes ${ }^{11}$, e tal abertura hermenêutica deve ser resolvida sob a ótica da eticidade da teoria dos precedentes. Consequentemente, ainda que os precedentes judiciais não substituam as leis na força de sua vinculação, podem por sua tradição e seu conteúdo, serem um paradigma decisório que firme um entendimento, de modo que, a interpretação do

11 O Código de Processo Civil de 2015 estabelece uma normatividade dos precedentes, mas não é expresso em conferir vinculação das cortes a seus próprios precedentes. A opção do legislador foi em conferir expressamente vinculabilidade dos tribunais intermediários e das instâncias inferiores, porém implicitamente é possivel verificar que existe essa possibilidade de vinculação. 
direito deve procurar ser convergente, em conformidade com a Constituição e os preceitos democráticos.

A teoria dos precedentes judiciais pode ser um elemento de se evitar turbulências sociais causadas por contradições decisórias, pois, a decisão equilibrada entre efetividade e estabilidade, atinge seu alvo, resolvendo a controvérsia judicial e aperfeiçoando a interpretação do direito (DWORKIN, 2001, p. 180).

Uma correta aplicação dos precedentes possue respaldo na importância dos tribunais em reduzir as indeterminações do texto normativo e conformar o discurso jurídico. Todavia, com a abertura principiológica do direito, as cortes são responsáveis por dar dinamismo aos mandamentos normativos, garantindo a efetividade do direito no tempo; mas também, por outro lado, constituem uma ameaça à unidade do direito, de forma que as decisões judiciais devem alcançar uma posição de elemento racionalizador do direito, ou seja, os tribunais ao lidarem com princípios estabelecem os fundamentos para a hermenêutica do direito (LARENZ, 1985).

A prática habitual de se decidir sobre o mesmo tema, eleva o nível da discussão jurídica e aprimora a solução aplicada sem que a decisão seja construída a partir do marco zero, ou seja, a decisão paradigma é o ponto de partida, mas não é a última palavra sobre o assunto. A construção argumentativa de um precedente, que é aplicado reiteradamente, petrifica e dá robustez à interpretação, de tal maneira que, para se derrubar um precedente posto e habitualmente aplicado, torna-se uma complexa tarefa hermenêutica. (FERRAZ JR, 2016, p. 87).

Portanto, a adoção de uma hermenêutica dos precedentes judiciais no direito brasileiro, em especial na vinculação vertical das cortes superiores aos precedentes, encontra respaldo pelos diversos fatores expostos; de dar racionalidade, aplicar o direito equitativamente, com igualdade, com coerência, e também, oferecer segurança jurídica aos jurisdicionados. 


\section{A SUPERAÇÃO DO PARADIGMA DE LEGISLADOR NEGATIVO PARA A ATUAÇÃO NORMATIVA DAS CORTES SUPERIORES POR MEIO DAS SENTENÇAS NORMATIVAS}

A virada linguística ou o giro hermenêutico do direito (CARVALHO NETTO; SCOTTI, 2012, p. 42; HABERMAS, 2002, s/p) trouxe desafios ao direito processual, de modo que este ramo do direito, além de se emancipar nos últimos anos, ganhou status de elemento condutor e realizador de direitos, e do próprio direito em si. O processo, por meio da decisão judicial, se tornou protagonista no Estado Constitucional, principalmente após a superação do paradigma positivista no direito. Como consequência, novos paradigmas do direito, como por exemplo, efetividade constitucional (BARROSO, 2010, p. 100), normatividade dos princípios (ALEXY, 2002, s/p), ética reflexiva (HABERMAS, 2002, s/p), irradiação dos direitos fundamentais (SARLET, 2010, s/p), virada hermenêutica (STRECK, 2014, $\mathrm{s} / \mathrm{p}$ ) dentre outros, tornaram a decisão judicial fonte que interpreta o direito a partir do texto para criar norma (LORENZETTI, 2009, p. 135).

$\mathrm{O}$ direito processual deixou de ser apenas uma garantia de não abuso do Estado, concretizando-se como, um meio efetivo e democrático de se realizar o direito. Para que haja a fluidez das normas é necessário unidade e continuidade dos aplicadores do direito, ou seja, as decisões judiciais não são, por si só, fontes do direito, mas matéria-prima que abastece a jurisprudência e tem em seu DNA a interpretação dos textos normativos. Portanto, o processo busca que a jurisdição seja efetiva e equitativa, de maneira que a legislação processual esteja preocupada com a formação (fundamentação) e a aplicação (caráter executivo e de vinculação) das decisões judiciais (TUCCI, 2004, p. 152).

O Código de Processo em sentido amplo, reunindo toda a legislação processual (constitucional e infraconstitucional), pode ser definido como as leis que 
regulamentam a garantia constitucional de Justiça contida na Constituição, servindo de instrumento de reivindicação dos particulares contra possíveis arbitrariedades do Estado, de modo que a Justiça é o objeto e a finalidade do Direito Processual (COUTURE, 1946, p. 34). O processo existe basicamente sob dois propósitos, para ser um facilitador da Justiça, e também garantir que a busca por Justiça viole no mínimo possível as liberdades individuais (CANARIS, 1989, p.82).

Do mesmo modo que o processo possui meios de flexibilizar a interpretação dos textos normativos, ampliando os poderes decisórios dos magistrados, deve possuir também elementos de barrar a discricionariedade interpretativa. A jurisdição constitucional, por meio de sua jurisprudência, promoveu a evolução das técnicas decisórias no sentido de dar efetividade às normas constitucionais, por outro lado, o processo infraconstitucional se constitucionalizou, adotando regras e princípios que consagram a interpretação (ZANETI, 2014, p. 101).

As jurisdições, constitucional e infraconstitucional, passam por uma aproximação dialógica que possibilita o crescimento e fortalecimentos das cortes superiores e das suas decisões. Esta aproximação das esferas jurisdicionais se dá devido à constitucionalização do processo e a importância das decisões judiciais proferidas pelas cortes constitucionais na conformação do direito infraconstitucional (ZANETI, 2014, p. 70). Portanto, quanto maior a comunicabilidade jurisprudencial e a atuação complementar das cortes, maior será a convergência processualinterpretativa que visa dar unidade e coerência ao Direito.

O constitucionalismo por meio da ideologia de direitos fundamentais processuais como: contraditório, devido processo legal, boa-fé objetiva, tutela jurisdicional efetiva e tempestiva, segurança jurídica, confiança justificada e todas as garantias de proteção das liberdades, são ornamentos intangíveis do direito processual que moldam sua estrutura procedimental de correção formal e sua estrutura material de justiça substancial (ZANETI, 2014, p. 85). Dentre os vários paradigmas que transformaram o direito processual, o principal deles pode ser 
considerado como sendo o Judicial Review12, já que a partir desse instituto, o direito passou a ser interpretado pelo Judiciário, dando origem ao controle de constitucionalidade em sua forma difusa, ou seja, a interpretação jurídica foi incorporada pelo direito processual, e dessa forma permitiu grande evolução desse ramo.

No Brasil, com advento da Constituição Republicana de 189113, este modelo foi incorporada ao sistema brasileiro e se tornou presença constante nas constituições posteriores. A partir dessa alteração, o Judiciário galgou espaço no contexto institucional democrático, consagrando-se o intérprete oficial da Constituição no Estado Constitucional. A revisão de atos políticos sob a ótica de instrumentos jurídicos almeja dar proteção aos princípios e valores constitucionais, tanto os de aspectos mais formais (princípio democrático, separação dos poderes, princípio republicano), quanto os de aspectos mais substanciais (liberdade, igualdade).

O controle de constitucionalidade em sua forma difusa, por meio do Judicial Review, e em sua forma concentrada, por meio das ações constitucionais, existiam desde a Constituição de 1891, no primeiro caso, e na Constituição de 1937, no que se refere ao controle concentrado. Entretanto, na CRFB/1988, tais sistemas, passaram a conviver no ordenamento brasileiro, de forma mais dialógica e sistêmica. Tal fato se deve, principalmente, ao aumento da judicialização,

12 Judicial Review é a capacidade do Poder Judiciário rever atos políticos-normativos dos outros poderes e dar interpretação segundo a constituição, é um modelo de fiscalização institucional que eleva a importância da interpretação constitucional e dita que é legítimo para tal feito. Teve origem nos EUA, tendo o caso Marbury vs Madson no ano de 1803, como um dos pioneiros.

13 Constituição da República dos Estados Unidos do Brasil, 24 de fevereiro de 1891. Art. 60 $\S 1^{\circ}$ alínea 'a' e 'b' que dizem: a) quando se questionar sobre a vigência ou a validade das leis federais em face da Constituição e a decisão do Tribunal do Estado lhes negar aplicação;b) quando se contestar a validade de leis ou actos dos governos dos Estados em face da Constituição, ou das leis federais, e a decisão do tribunal do Estado considerar válidos esses atos, ou essas leis impugnadas; BRASIL. Constituição anteriores. Legislação histórica Disponível em: <http://www4.planalto.gov.br/legislacao/legislacao-historica/constituicoes-anteriores-1>. Acesso em: 29 nov. 2016. 
decorrente do garantismo constitucional14, e um fortalecimento institucional decorrente do período democrático, pós regime ditatorial (STRECK, 2014, p. 581).

No âmbito do direito processual, tal conjuntura se reflete na formação jurisprudencial da jurisdição constitucional e na virada dogmática no processo, em que as cortes constitucionais passaram a dar interpretação às leis e criar normas, se tornado a chave para o funcionamento do Estado Democrático de Direito. No Brasil, desde a Constituição brasileira de 1824, por meio do poder moderador, busca-se uma instituição que zele pela harmonia e equilíbrio entre os poderes políticos (CONTINENTINO, 2015, p. 97). Contudo, na nova perspectiva processual, o Judiciário passou a realizar esta função.

A CRFB/1988 é pródiga em fornecer mecanismos processuais de defesa dos direitos, e meios de se discutir questões jurídicas em níveis constitucionais. Portanto, com tamanho estímulo à judicialização, a atuação das cortes cresceu significativamente, de forma que nos primeiros anos da Constituição, a corte constitucional atuava apenas como legislador negativo, declarando a validade, a invalidade ou a anulabilidade de normas postas ao seu crivo de controle.

Quando a corte se pronuncia declarando que determinada norma é constitucional ou inconstitucional, se tem configurado, a manutenção desta no ordenamento ou sua total extirpação. Contudo, o problema surge quando a exclusão de determinada norma inconstitucional causa instabilidade social gravosa, e da

14 Para Ferrajoli, o garantismo é uma teoria jusfilosófica que pode ser visto sob três formas: (i) a primeira, como modelo normativo de direito, caracterizado no plano epistemológico como técnica de maximização de liberdades e no plano jurídico uma vinculação estatal de garantir direitos dos cidadãos; (ii) em uma segunda acepção, o garantismo de Ferrajoli é visto como uma teoria jurídica da validade, da efetividade e da vigência, dentro desta perspectiva há uma redefinição destes conceitos, adotando o modelo constitucional e o funcionamento efetivo do mesmo, existe uma convergência entre os conceitos de validade e efetividade, mas ainda sim há distinção, dentro desta concepção o direito deve ser formalmente e materialmente válido; (iii) a terceira concepção o garantismo é visto como filosofia política que impõe ao Direito e ao Estado a carga de sua justificação externa, nesta concepção, a proposta do garantismo é a separação entre direito e moral e justiça e validade. Para o presente artigo adotar-se à visão garantista sob o espeque da teoria jurídica que promove a convergência entre validade e efetividade. 
mesma forma quando a corte lida com a questão da omissão inconstitucional, ou seja, quando a ausência de atuação do Estado configura uma inércia vedada pelo texto constitucional (SOUSA FILHO, 2016, p. 41).

Para estes casos, a jurisprudência demonstrou que a simples invalidação/validação de normas pelo Poder Judiciário é falha e insuficiente, pois, não resolve a omissão constitucional, e também não resolve casos em que a retirada da norma inconstitucional permite lacunas perigosas, o chamado vácuo normativo. Para tais casos são necessário que a interpretação dada pelo tribunal preencha as lacunas normativas com preceitos constitucionais pré estabelecidos, configurando uma atuação normativa das cortes, superando o paradigma de simples legislador negativo (SOUSA FILHO, 2016, p. 50).

O Poder Judiciário, precipuamente na jurisdição constitucional, passou a corrigir omissões legislativas com sentenças normativas que não apenas atuavam de forma binária (invalidando ou convalidando instrumentos normativos). A prática jurisprudencial demonstrou que era necessária uma atuação normativa-interpretativa no sentido de dar complementariedade, coerência e unidade ao ordenamento, pois, havia casos em que a invalidação ocasionava uma situação tão gravosa quanto a manutenção da norma inconstitucional. E, nos casos de convalidação, havia normas que não eram completamente constitucionais, e por isso, recebiam um tratamento hermenêutico para se adequar a realidade jurídica do nosso ordenamento.

As cortes superiores têm a possibilidade de criação normativa e não criação legislativa, e mesmo assim, tal atuação deve ocorrer quando a omissão cause fatos jurídicos que lesem princípios e valores constitucionais (SOUSA FILHO, 2016, 152). Desta conjuntura, surge no Brasil a possibilidade de aplicação das sentenças normativas que visam transformar a lei dentro da hermenêutica constitucional e não eliminá-las, ou seja, a função normativa das cortes constitucionais opera em dois sentidos: (i) ação de estímulo ao Poder Legislativo, apontando as diretrizes da 
interpretação constitucional para a feitura de leis; e (ii) cooperação institucional de complementariedade do escopo normativo (CALAMANDREI, 1990, p. 132).

As leis 9.868/1999 e 9.882/1999 trataram do tema das sentenças normativas em seus artigos, 27 e $28 \S$ único $^{15}$ (Lei da ADI) e no art. $10 \S 3^{\circ 16}$ (Lei da ADPF), estabelecendo: (i) a técnica da modulação temporal dos efeitos; (ii) a interpretação conforme a Constituição; (iii) declaração parcial de inconstitucionalidade sem redução de texto; (iv) fixando o modo de interpretação; e (v) dando eficácia e vinculabilidade da decisão a todo o poder público.

No mesmo caminho, o instituto do Mandado de Injunção ${ }^{17}$, de forma paralela, acompanhou o fortalecimento do controle de constitucionalidade e evoluiu a partir da construção jurisprudencial da corte constitucional brasileira. Recentemente, o mandado de injunção também passou a ter uma lei que regula seu processo e julgamento (BRASIL, 2016). A lei do mandado de injunção, em seus artigos: $8^{\circ} ; 9^{\circ}$ e $11^{\circ} 18$, estabelece um poder normativo-decisório das cortes

15 Art. 27. Ao declarar a inconstitucionalidade de lei ou ato normativo, e tendo em vista razões de segurança jurídica ou de excepcional interesse social, poderá o Supremo Tribunal Federal, por maioria de dois terços de seus membros, restringir os efeitos daquela declaração ou decidir que ela só tenha eficácia a partir de seu trânsito em julgado ou de outro momento que venha a ser fixado. Art. 28. Dentro do prazo de dez dias após o trânsito em julgado da decisão, o Supremo Tribunal Federal fará publicar em seção especial do Diário da Justiça e do Diário Oficial da União a parte dispositiva do acórdão. Parágrafo único. A declaração de constitucionalidade ou de inconstitucionalidade, inclusive a interpretação conforme a Constituição e a declaração parcial de inconstitucionalidade sem redução de texto, têm eficácia contra todos e efeito vinculante em relação aos órgãos do Poder Judiciário e à Administração Pública federal, estadual e municipal. (BRASIL. Lei no 9.868, de 1999).

16 Art. 10. Julgada a ação, far-se-à comunicação às autoridades ou órgãos responsáveis pela prática dos atos questionados, fixando-se as condições e o modo de interpretação e aplicação do preceito fundamental. $\S 3^{\mathrm{a}} \mathrm{A}$ decisão terá eficácia contra todos e efeito vinculante relativamente aos demais órgãos do Poder Público.

17 Art. $5^{\circ}$, inciso LXXI da Constituição Federal, conceder-se à mandado de injunção sempre que a falta de norma regulamentadora torne inviável o exercício dos direitos e liberdades constitucionais e das prerrogativas inerentes à nacionalidade, à soberania e à cidadania. (BRASIL, Constituição de 1988).

18 Art. $8^{\circ}$ Reconhecido o estado de mora legislativa, será deferida a injunção para: [...] II estabelecer as condições em que se dará o exercício dos direitos, das liberdades ou das prerrogativas reclamados ou, se for o caso, as condições em que poderá o interessado promover ação própria visando a exercê-los, caso não seja suprida a mora legislativa no prazo determinado. 
superiores. Portanto, a conjuntura destes fatores dá sustentação para a utilização da técnica decisória das sentenças normativas pelo Poder Judiciário.

Tais sentenças (normativas, manipulativas, modificativas ou intermédias), segundo a classificação da doutrina italiana, compõe o gênero que é subdividido em espécies, as quais podem ser classificadas em: (i) Sentenças Exortativas (são as que mantém a eficácia da lei declarada inconstitucional enquanto não existir uma alteração provinda do legislador); (ii) Sentenças Interpretativas (sem reformar o texto, a corte, diante das várias possibilidades interpretativas, escolhe uma em conformidade com a Constituição); (iii) Sentenças Aditivas (em caso de normas incompletas a corte atua complementando o sentido do texto, para suprir a omissão legislativa, criando uma regra, e adequando a norma à Constituição) e (iv) Sentenças Substitutivas (diante da inconstitucionalidade da lei ocorre um vácuo normativo perigoso que a corte adota a manutenção provisória da lei inconstitucional ou cria uma regra jurídica provisória que supra o vácuo normativo, essas duas medidas podem ser tomadas em separado ou simultaneamente) (SOUSA FILHO, 2016, p. 111-118; STRECK, 2014, s/p).

$\mathrm{Na}$ Jurisdição Constitucional, as sentenças normativas declaram a inconstitucionalidade da lei, mas, em contrapartida, ditam uma solução jurídiconormativa que extrapola o texto legislado, operando no âmbito da normatividade, mas ainda sim dentro de uma veste constitucional, nesse sentido, é permitido apenas completar a norma com preceitos constitucionais já existentes, de forma que as

[...] Art. 9 A decisão terá eficácia subjetiva limitada às partes e produzirá efeitos até o advento da norma regulamentadora. $\S 1^{\circ}$ Poderá ser conferida eficácia ultra partes ou erga omnes à decisão, quando isso for inerente ou indispensável ao exercício do direito, da liberdade ou da prerrogativa objeto da impetração. $\S 2^{\circ}$ Transitada em julgado a decisão, seus efeitos poderão ser estendidos aos casos análogos por decisão monocrática do relator. [...] Art. 11. A norma regulamentadora superveniente produzirá efeitos ex nunc em relação aos beneficiados por decisão transitada em julgado, salvo se a aplicação da norma editada lhes for mais favorável. Parágrafo único. Estará prejudicada a impetração se a norma regulamentadora for editada antes da decisão, caso em que o processo será extinto sem resolução de mérito. 
técnicas decisórias utilizadas nas sentenças normativas almejam conformar o texto legal em uma ideia de complementariedade (SOUSA FILHO, 2016, p. 255).

As cortes de jurisdição infraconstitucional, como o STJ, também adquiriram a prerrogativa de se utilizar de técnicas decisórias, como por exemplo, o art. 927, § $3^{0^{19}}$, estabelecendo a possibilidade da modulação temporal dos efeitos da decisão judicial. Desta forma, com a constitucionalização do processo, ocorre naturalmente um crescimento institucional das cortes superiores, que ganham em capacidade decisória-normativa. O Código de Processo Civil de 2015 é essencial instrumento de convergência das jurisdições, pois estabelece a comunicabilidade e a complementariedade destas.

Portanto, as técnicas decisórias, em especial, as sentenças normativas, constituem importante tecnologia de constitucionalização do processo, e também dos demais ramos do direito, pois, de um lado, a liberdade manipulativa e interpretativa do direito almeja garantir justiça das decisões, e de outro, a atuação normativa, e não legislativa, por meio da construção jurisprudencial que colmata lacunas, visa dar equilíbrio e estabilidade ao direito. A verticalização do uso das técnicas decisórias, para além da jurisdição constitucional constitui uma nova realidade processual.

\section{A HERMENÊUTICA DOS PRECEDENTES JUDICIAIS COMO CONTRAPONTO AO USO DAS TÉCNICAS DECISÓRIAS DAS SENTENÇAS NORMATIVAS NA JURISDIÇÃO CONSTITUCIONAL E INFRACONSTITUCIONAL}

19 Art. 927. Os juízes e os tribunais observarão: § 3o Na hipótese de alteração de jurisprudência dominante do Supremo Tribunal Federal e dos tribunais superiores ou daquela oriunda de julgamento de casos repetitivos, pode haver modulação dos efeitos da alteração no interesse social e no da segurança jurídica. (BRASIL, Código de Processo Civil, Lei 13.105, de 16 de março de 2015). 
As cortes superiores e os tribunais constitucionais têm pela frente o desafio de enfrentar, cada vez mais, questões políticas em decisões judiciais que geram efeitos diversos em vários planos da sociedade (DWORKIN, 2001, p. 22). Todavia, o papel dos tribunais, ao contrário do que aparenta, não é mais aberto que o juiz de primeiro grau; são formas distintas de julgamento, em que; os juízes de primeiro e segundo grau possuem maior vinculação ao direito posto e as decisões préexistentes sobre a matéria, enquanto os tribunais têm um maior compromisso com a estabilidade e a segurança do direito (MARINONI, 2016, p.177).

Sob a nova perspectiva de efetividade dos direitos, as Constituições tornaram-se projetos de realização social, em duas bases: o constitucionalmente necessário, na forma de mandamentos, e o constitucionalmente impossível, na forma de proibições (ALEXY, 2002, p. 89). A decisão judicial proferida por cortes superiores tem muito mais o condão de delinear a efetividade dos mandamentos e estabelecer os limites das proibições do que a própria atividade do Poder Legislativo. Isto porque, a interpretação dos textos normativos é muito mais prerrogativa do Poder Judiciário, como força contra-majoritária (defesa dos direitos fundamentais), do que do Poder Legislativo que possui maior abertura discricionária e força democrática para legislar de maneira mais aberta e cediço as forças majoritárias (COSTA, 2013, p. 172-175).

As influências políticas e morais no direito, por meio dos valores, desenham uma nova separação entre os poderes do Estado, sendo que o Poder Judiciário é o poder que detém a prerrogativa de proteger e garantir os direitos fundamentais, independentemente do interesse público envolvido, daí seu caráter contramajoritário de defesa dos interesses individuais (SOUSA FILHO, 2016, p. 43). Os demais poderes tem a legitimidade democrática de representantes da maioria e, por isso, podem tomar decisões políticas, respaldados por este atributo. A tensão surge quando o poder contra majoritário tem pela frente, decisões que necessitam entrar 
na órbita da legitimidade democrática. Portanto, o Judiciário não pode agir na esfera política sem as devidas amarras que limitam sua atuação.

Os tribunais, em sua função constante de reformatação do direito, necessitam de limites éticos além dos limites constitucionais, pois este segundo também é um limite que necessita de interpretação (DWORKIN, 2002, p. 208). A teoria interpretativista proposta por Ronald Dworkin, coloca o juiz, não como oráculo da doutrina, mas, como homem que responde diferentes estímulos sociais e pessoais, passível de uma conduta circunscrita por valores (DWORKIN, 2002, p. 136).

A Constituição, ao fundir questões jurídicas e políticas, traz para o campo das decisões judiciais, uma profusão política de argumentos que levam o direito a uma erosão de valores próprios (DWORKIN, 2001, p. 46). A relação entre política, direito e moral não pode ser apenas resolvida por proposições jurídicas, sob o risco de perder equilíbrio. Portanto, o direito nas decisões judiciais proferidas pelos tribunais, deve ser moderado, consequência das práticas judiciais reiteradas (jurisprudência), decorrentes das próprias decisões e direcionadas sobre o princípio norteador constitucional de projeto de Estado.

Portanto, a abertura hermenêutica e a capacidade normativa na aplicação do direito pelos tribunais, necessita de um outro extremo que funcione como limite da atividade jurisdicional. O respeito aos precedentes pelas próprias cortes que o firmam equilibra a abertura interpretativa e concretiza a ideia de continuidade. Para que o direito sobreviva à realidade histórica, política e social e também sobreviva aos efeitos do tempo, deve haver sistemas de frear distorções interpretativas sem obstaculizar a evolução natural do direito e diminuir seu papel contra-majoritário (MARINONI, 2008, p. 41-47).

A lei não deve ser o único limite à interpretação, deve haver também por parte dos tribunais uma ética processual que respeite as decisões emanadas por estes órgãos, demonstrando: (i) compromisso com o projeto de Estado e sociedade estipulado na Constituição; (ii) equilíbrio entre a ampla possibilidade interpretativa, 
decorrente da virada hermenêutica do direito (efetividade da Constituição) em contraponto à solidez racional extraída do respeito aos precedentes proferidos pelas próprias cortes; (iii) construção de uma jurisprudência que traga a ideia de continuidade, e do compromisso em alcançar uma interpretação convergente na aplicação do direito.

A transformação pela qual passa a Jurisdição Constitucional, por meio da edificação jurisprudencial do STF nos últimos anos e das contribuições do direito comparado sobre as sentenças normativas, permite delinear alguns limites e sedimenta a possibilidade do uso de técnicas decisórias pela jurisdição infraconstitucional, sendo que o próprio Código de Processo Civil de 2015, em seu art. $927, \S 3^{\circ}$, consagra tal possibilidade.

Nesse sentido, no âmbito do direito substancial, a inviabilidade do exercício de algum direito materialmente fundamental, justifica a produção de normas pelas cortes superiores infraconstitucionais, principalmente adequando a legislação federal ao entendimento da corte constitucional. Já no âmbito formal, a legislação processual se constitucionalizou e o Código de Processo Civil de 2015, trouxe a possibilidade dos tribunais superiores adquirirem ainda mais autonomia em seus julgamentos, fixando precedentes e manipulando a interpretação sob a sua jurisdição (SOUSA FILHO, 2016, p. 250).

Se por um lado as cortes superiores se utilizaram de técnicas decisórias que em certa medida ampliam sua função interpretativa-normativa, por outro, no que tange à vinculação destas cortes aos seus próprios precedentes, não houve significativos avanços. A hermenêutica dos precedentes é um contraponto teórico que equilibra a utilização das técnicas decisórias, tanto na esfera da jurisdição constitucional pelo STF, quanto na esfera da jurisdição infraconstitucional pelo STJ.

A constitucionalização do processo demanda que o direito, na sua feição de poder contra majoritário (defensor das regras do jogo democrático e protetor dos direitos fundamentais), seja utilizado com equilíbrio para não comprometer a 
estrutura do Estado Constitucional. A capacidade normativa da jurisdição encontra meios de manipular técnicas decisórias para encontrar soluções dentro do permitido e do justo-constitucional.

O desafio que se coloca está em como contrapor limites entre as funções políticas e jurídicas das cortes superiores. A atuação normativa das cortes devem obedecer ao critério de proporcionalidade e mínima intervenção nas questões políticas de cunho democrático (PULIDO, 2013, p. 159). Portanto, as sentenças normativas têm o escopo de garantir segurança jurídica, estabilidade social e também dar continuidade e unidade ao direito.

O equilíbrio entre a utilização de técnicas que abrem a interpretação jurídica e técnicas que fecham a coerência do ordenamento, encontra fundamento de aplicabilidade nos próprios valores constitucionais. Como forma de equilibrar o uso das duas técnicas decisórias, é necessário que a atuação do Judiciário, em especial, das cortes superiores, esteja em acordo com o programa normativo constitucional, não podendo agir em desconformidade com este norte. Segundo Friedrich Muller, o programa normativo abarca o dever de legislar, e por outro lado, objetiva a adequação da lei com a realidade, corroborando o papel do Judiciário e permitindo que a interpretação adeque o direito aos princípios constitucionais (MULLER, 2005, p. 130-135).

Em sentido complementar, a hermenêutica dos precedentes tem uma vertente de fechamento do ordenamento, mas também tem válvulas de escape para promover a evolução e a continuidade do direito. Portanto, por meio da habitualidade das decisões, as cortes sedimentam sua interpretação. Contudo, a formação do precedente, que ocorre de forma espiral, desde as instâncias inferiores até as cortes, garante o processo democrático de discussão e debates para se construir e fundamentar a decisão, de modo que a argumentação tende a ser esgotada até se construir um precedente, mesmo porque, o precedente só completa sua formação 
quando é aplicado em outra decisão com simetria em relação à categoria de fatos (PERELMAN; OLBRECHTS-TYTECA, 2005, p. 90).

A capacidade interpretativa não fica comprometida devida à vinculabilidade aos precedentes, pois a corte pode se utilizar de diferentes técnicas, próprias da hermenêutica dos precedentes para alterar determinado precedente. As técnicas de superação e distinção, que são utilizadas para abandonar um precedente e demonstrar que um determinado caso não se aplica ao precedente posto sobre aquela categoria de fatos, dão à hermenêutica dos precedentes certa flexibilidade interpretativa que permite às cortes alterarem seu entendimento, respeitando uma ordem hermenêutica. Portanto, esta técnica permite que novos fatos sejam resolvidos a partir de novos parâmetros jurídicos, mas, a observação das decisões passadas (precedentes) deve ser um ponto de referência, isto é, afastada, superada ou declarada inconstitucional de maneira fundamentada (ABBOUD; NERY JR, 2013, p. 421).

A hermenêutica dos precedentes atua em três desdobramentos principais: (i) dar previsibilidade e confiança justificada ao direito; (ii) dar unidade e coerência ao direito, permitindo que todo o ordenamento aponte na mesma direção; e (iii) permitir a continuidade evolutiva do direito, proporcionando espaços para a transformação das normas pela via da interpretação, respeitados critérios hermenêuticos (MARINONI, 2014, p. 95).

Por outro lado, as sentenças normativas têm uma vertente de evolução do direito por meio da interpretação, mas também tem saídas que fecham o ordenamento, como por exemplo, o efeito proibitivo de inovar no mundo jurídico, atuar limitados por preceitos constitucionais e apenas em caso de omissões que gerem inconstitucionalidade.

O preenchimento normativo, por meio das sentenças manipulativas, é uma técnica que visa resolver o caso colocado sobre o poder decisório das cortes superiores, mas também fazer o direito avançar por meio da interpretação. Ou seja, 
o texto normativo, para acompanhar a evolução social, necessita de constantes ajustes temporais para garantir que a norma seja efetiva no transcurso do tempo, sob pena de o direito posto se tornar obsoleto e ineficaz (SOUSA FILHO, 2016, p. 181).

As sentenças normativas, por um lado, representam a liberdade interpretativa, mas por outro, é circunscrita por parâmetros hermenêuticos que determinam o limite de atuação das cortes. Assim como a hermenêutica dos precedentes, as sentenças normativas atuam sob três desdobramentos que são: (i) permitir a continuidade evolutiva do direito, permitindo espaços para a transformação das normas pela via da interpretação, respeitados critérios hermenêuticos; (ii) resolver as lacunas interpretativas e corrigir as inconsistências dos textos normativos, visando dar completude ao ordenamento; e (iii) dar efetividade ao direito e permitir que as normas tenham seus efeitos irradiados e concretizados no plano dos fatos.

Não por coincidência, o item (iii) dos desdobramentos da hermenêutica dos precedentes é o mesmo do item (i) das sentenças normativas, ou seja, às duas modalidades decisórias tem essa premissa em seu núcleo teleológico. A continuidade evolutiva do direito perpassa pela constante interpretação, mas, para que essa reformatação constante do direito ocorra é necessário haver limites que conformem a decisão judicial, seja ela um precedente judicial ou uma sentença normativa.

Fazendo a intersecção dos desdobramentos das sentenças normativas e da hermenêutica dos precedentes, chega-se aos parâmetros hermenêuticos que dão base para a construção de uma decisão judicial justa, estável e correta. Portanto, a hermenêutica dos precedentes, assim como a utilização das sentenças normativas, não necessita de positivação em textos legislados e não transforma a configuração de legalidade que existe em nosso ordenamento, mas, visam adaptar o direito às mudanças sociais, sem esvaziar a autonomia do direito. A lei, por si só, não garante segurança jurídica, pois, o tempo atua contra a rigidez da legalidade e deteriora o 
sentido dos textos, contudo, a interpretação molda o texto em conformidade com a realidade fática.

A utilização dialógica das técnicas decisórias, da hermenêutica dos precedentes e das sentenças normativas, respeita os valores constitucionais e atua no sentido de dar completude e evolução ao direito. Todavia, no ordenamento jurídico pátrio ainda não há equilíbrio entre às duas modalidades, de forma que não existe um reconhecimento institucional da atuação normativa dos tribunais e também não há um efetivo respeito destes perante seus próprios precedentes. Portanto, é essencial adotar um dever de respeito aos próprios precedentes por parte das cortes superiores para que exista uma estabilidade na aplicação das duas técnicas e uma estabilidade constitucional-hermenêutica no direito, do mesmo modo, as sentenças normativas precisam de reconhecimento ideológico e metodológico pelas cortes para que sejam aplicadas corretamente.

Enfim, é necessário a utilização das duas técnicas de maneira sistêmica e criteriosa, pois desta forma evita-se a discricionariedade e a interpretação jurídica desprovida de limites.

5. A ATUAÇÃo dOS ATORES DO STF E DO STJ DIANTE DA APLICAÇÃO DAS DUAS TÉCNICAS DECISÓRIAS: DISCUSSÃO DE CASOS EM QUE AS CORTES FORAM PRÓdIGAS EM PRODUZIR NORMAS, MAS CONTIDAS EM FIXAR LIMITES

Neste tópico serão analisado decisões judiciais do STF e do STJ que exemplificam a utilização de forma insuficiente, ou não, das técnicas decisórias aqui abordadas. O objetivo é detalhar a aplicação de tais técnicas e tecer criticas a respeito de seu uso, seja por falta de critérios, excessos interpretativos, ou mesmo desrespeito as condicionantes de aplicação de ambas. Da mesma forma, também 
será observado a oportunidade de se utilizar as duas técnicas em complementariedade promovendo a coerência e a integridade do direito.

Em um primeiro momento o olhar se voltará à técnica decisória das sentenças aditivas e seu uso pelas cortes superiores do STF e STJ. Nesse sentido, a exploração argumentativa focará em duas recentes decisões que são: (i) A decisão do STF versando sobre o cumprimento da pena em regime fechado, na hipótese de inexistir vaga em estabelecimento adequado a seu regime (BRASIL, STF, Recurso Extraordinário no 641.320/RS, 2016); (ii) A decisão do STJ que fixou critérios normativos para a publicidade voltada a criança e adolescentes (BRASIL, STJ, Recurso Especial no 1.558.086/SP, 2016).

Posteriormente será debatido a necessidade de utilização da hermenêutica dos precedentes judiciais como meio de dar continuidade a essas decisões firmadas pela técnica das sentenças normativas e permitir que o direito matenha sua evolução interpretativa com respeito a coerência e unidade do ordenamento.

Pois bem, no que se refere ao STF, a decisão contempla a um Recurso Extraordinário que pretendeu discutir a possibilidade de reduzir a pena condenatória e fixar a prisão domiciliar enquanto não existir estabelecimento destinado ao regime semiaberto que atenda todos os requisitos da Lei de Execução Penal. A controvérsia chegou ao STF por via de Recurso Extraordinário, e no próprio voto do relator, o Ministro Gilmar Mendes foi proposto um caráter aditivo a decisão.

A decisão fixa os paradigmas gerais sobre o tema, e depois verifica a incidência destas proposições para o caso individual. Em um primeiro momento, o Min. Relator refuta a possibilidade de manutenção de um sentenciado no regime mais gravoso por falta de vagas no regime adequado a sua pena, pois, viola diretamente o princípio da legalidade estrita e da individualidade penal. Posteriormente é enfrentado as consequências do direito a não ser mantido em estabelecimento destinado ao regime mais gravoso. 
Nesse entendimento, as decisões anteriores a esta, praticamente se dividiam em dois caminhos: (i) manutenção do sentenciado em regime mais gravoso ao que teria direito (violação constitucional); (ii) colocação imediata deste em regime menos gravosos, prisão domiciliar), promovendo um salto no percurso de progressão de regime (também uma violação constitucional, pois, dá tratamento distinto a direitos iguais).

Diante deste quadro, a corte atuou para minimizar a omissão constitucional e a insuficiência legislativa, para isto, fixou as seguintes normas: (i) a falta de estabelecimento penal adequado não autoriza a manutenção do sentenciado em regime prisional mais gravoso; (ii) Os juízes da execução penal poderão avaliar os estabelecimentos destinados aos regimes semiabertos e aberto, para qualificação como adequados a tais regimes; (iii) havendo déficit de vagas, deverá ser determinado a saída antecipada do sentenciado no regime com falta de vagas, ou, a liberdade eletronicamente monitorada ao sentenciado que sai antecipadamente ou é posto em prisão domiciliar por falta de vagas, ou por fim, o cumprimento de penas restritivas de direito e/ou estudos ao sentenciado que progride ao regime aberto; (iv) até que seja estruturadas as medidas alternativas propostas, poderá ser deferida a prisão domiciliar ao sentenciado.

Portanto, a corte determinou que haja um escalonamento na progressão dos regimes e a falta de vagas obedeça uma sequência respeitando prioridades, de modo que os sentenciados que estão mais próximos de atingir esse benefício o consigam, e desta forma evitando que sentenciados saltem a ordem da progressão. Ou seja, o STF proferiu uma senteça aditiva, que por definição ocorre quando, em caso de normas incompletas a corte atua complementando o sentido do texto, para suprir a omissão legislativa, criando uma regra, e adequando a norma à Constituição.

No mesmo sentido, o STJ em sede de Recurso Especial também fixou condicionantes que podem ser considerada uma espécie das sentenças normativas, porém não uma sentença aditiva (gênero), e sim uma sentença interpretativa, que 
são, as decisões que; sem reformar o texto, a corte, diante das várias possibilidades interpretativas, escolhe uma em conformidade com a Constituição. Nesse acórdão o STJ fixou limites à publicidade destinada a criança, interpretando vários dispositivos textuais, como o Código de Defesa do Consumidor e o Estatuto da Criança e do Adolescente, para produzir um entendimento convergente com os preceitos constitucionais.

O dilema posto sob o crivo da corte versava sobre uma propaganda vinculada em âmbito nacional realizado por uma empresa de alimentos que vinculava a venda um relógio à compra de produtos alimentícios, e tal publicidade era voltada exclusivamente para crianças. A conjuntura do ordenamento jurídico brasileiro não era clara em proibir esse denominado marketing infantil, porém, a corte utilizou (não de maneira expressa como o STF) a técnica decisória das sentenças normativas/manipulativas, ou seja, por meio da interpretação dos vários instrumentos normativos de proteção ao consumidor e a criança, o tribunal da cidadania estabeleceu uma proibição à publicidade infantil que não constava em nenhum texto normativo, e assim, construiu um novo horizonte de interpretação que determina o modo vinculante de interpretar sistemicamente os estatutos de proteção da criança e do adolescente e do consumidor.

Diante dos exemplos expostos de decisões que se utilizaram da técnica das sentenças normativas pode-se concluir que esta técnica possui aderência ao sistema constitucional brasileiro e constituem um importante instrumento de efetivação da Constituição e dos direitos fundamentais.

Por outro lado, a crítica que se faz à utilização das sentenças normativas pelas cortes superiores consiste na falta de criteriologia em sua aplicação, consequentemente, as decisões proferidas nesse espaço hermenêutico deixam a sensação na comunidade jurídica de que, tudo é permitido, e de que, a decisão sobre o uso de tal técnica é discricionário. De fato, nas duas decisões analisadas, não foram enfrentadas com densidade argumentativa condicionantes para sua aplicação, 
o que de fato ocorreu, foi a possibilidade de utilização e logo se partiu para definir a nova interpretação, sem o cuidado de demonstrar a necessidade do uso de tal técnica, visto que, seu uso deve ser uma exceção, justamente por ser uma manipulação do ordenamento pelo poder contra-majoritário.

Em relação à hermenêutica dos precedentes inúmeros são as inconsistências na aplicação desta técnica tanto no STJ, quanto no STF. Os tribunais não demonstram critérios no seu uso, mas sim, desobediência ao parâmetros básicos de utilização desta técnica. As cortes por meio de seus ministros aplicam de forma inconsistente a hermenêutica dos precedentes judiciais, justamente por apresentarem dificuldade de observar os critérios para formação, aplicação, e não aplicação do preocedentes (distinção, superação e inconstitucionalidade).

No que concerne ao STF, a controvérsia que recentemente foi colocada sobre o âmbito de decisão da corte versava sobre a presunção de inocência e desnecessidade de esgotamento das instâncias recursais para o cumprimento da pena. Nessa esteira, a corte ao mudar de entendimento deveria confrontar a decisão antiga (BRASIL, STF, Habeas Corpus $n^{\circ}$ 84.078/MG) que dizia que a presunção de inocência vai até o trânsito em julgado da decisão de ultima instância e superar seu entendimento enfrentado e superando seus argumentos. Porém, a corte no julgamento do HC no 126.292/SP (BRASIL, STF, Habeas Corpus $n^{\circ}$ 126.292/SP), poucas vezes menciona a decisão que a precedia e não a revoga expressamente, muito menos justificando ser um caso de distinção. Dito isto, este precedente firmado causou o contrário do seu propósito de ser um fator de estabilidade e segurança, isto é, a vagueza e a imprecisão técnica causou oscilações em todo o ordenamento. No $\mathrm{HC} \mathrm{n}^{\circ}$ 140.213/SP (BRASIL, STF, Habeas Corpus $\mathrm{n}^{\circ}$ 140.213/SP), o Ministro Relator Luiz Fux alegou dúvidas em relação a aplicação ou no do precedente ao caso, ou seja, não havia fundamentos para sua distinção e não havia condições formais para sua superação, o Ministro apenas alegou que o caso carecia de reflexão e afastou o precedente. 
Logo, o que se viu foi que diante de uma dúvida na aplicação ou não de um precedente o julgador optou por não aplicá-lo, sendo que o correto partiria de duas opções: (i) em caso de dúvidas da aplicação do precedente, ou não, este deve submeter o caso ao plenário, pois a dúvida não se enquadra nos casos aqui já debatidos de inaplicabilidade dos precedentes (superação, distinção, e inconstitucionalidade) lembrando que a superação apenas deve ser realizada pelo plenário ou turma que o proferiu, mas nunca por um juiz singular; (ii) e a outra opção seria demonstrar que o precedente não se aplica ao caso em tela e demonstrar que ocorre uma distinção ou uma inconstitucionalidade, enfrentando os argumentos do caso.

Ainda na mesma esfera desse tema, alguns meses após ser firmado esse precedente, o Ministro Celso de Mello em decisão liminar monocrática no $\mathrm{HC}^{\circ}$ 135.100/MG (BRASIL, STF, Habeas Corpus $n^{\circ}$ 135.100/MG) entendeu que, embora respeitabilíssima a decisão tomada em plenário não se impõe à compulsória observância dos juízes e tribunais em geral, dito isto, como justificativa, o ministro "escolheu" por não segui-la, ou seja, um único ministro resolve não seguir um precedente firmado em plenário, sem apresentar qualquer justificativa ou fundamentação dialógica com a decisão precedente. Portanto, nesse exemplo, um julgador de maneira singular não aplicou um precedente sem distingui-lo, sem fundamentar pela sua inconstitucionalidade, ou submetê-lo ao plenário para posterior revogação.

Diante do exposto, os exemplos trazidos ao palco da discussão confirmam que as cortes superiores têm dificuldade em respeitar suas proprias decisões, não reconhecendo uma vinculabilidade e não enfrentando os argumentos que formaram as razões de decidir de uma decisão.

Em conclusão, existe uma necessidade das cortes superiores se reconhecerem vinculadas aos seus próprios precedentes, e esta técnica é aderente ao ordenamento 
jurídico, porém necessita ser utilizada de forma adequada para atingir sua finalidade e não causar distorções sistêmicas.

Por fim, as duas técnicas tem amplo uso pelos tribunais superiores, contudo necessitam de um maior rigor técnico e criteriológico em sua utilização, para posteriormente atuarem de modo dialógico-complementar, aprimorando a hermenêutica jurídica e servindo de contrapeso à liberdade interpretativa no direito.

\section{CONSIDERAÇÕES FINAIS}

O presente artigo se debruçou na questão das cortes superiores respeitarem seus precedentes como técnica decisória simétrica à técnica das sentenças normativas, ou seja, diante de uma concepção de ampliação e criação normativa, é necessário adotar métodos decisórios que equilibrem os efeitos hermenêuticos produzidos. Nesse sentido, concluiu-se que o respeito aos precedentes pelas cortes superiores é compatível com o sistema jurídico-constitucional brasileiro, conforme os preceitos constitucionais e processuais.

Dessa maneira, assim como acontece com a modelo de precedentes normativos que exerce a vinculação horizontal, é possível extrair uma vinculação vertical no âmbito das cortes, pois, quem cria os precedentes também deve seguilos. Nessa percepção, o artigo se propôs a demonstrar que a hermenêutica dos precedentes pode ser fator teórico que delimite as decisões judiciais dos tribunais, de modo que estas devem atender certos critérios de operabilidade assim como o uso das sentenças normativas.

Por conseguinte, a evolução jurídica da decisão judicial caminhou no sentido de ampliar a capacidade decisória das cortes, por meio das sentenças normativas, como técnica decisória que visa solucionar vácuos normativos e omissões inconstitucionais. Todavia, não houve uma preocupação de contrapor a estas sentenças normativas, uma outra técnica decisória que equilibre a liberdade 
interpretativa de maneira racional, ou mesmo fixar critérios para sua utilização. Contudo, a hermenêutica dos precedentes tem o condão de ser esta técnica, por toda a concepção interpretativista do direito.

Portanto, da mesma forma que as sentenças normativas evoluíram da jurisprudência (por meio da jurisdição constitucional) para os textos legislados e para a jurisdição infraconstitucional, a técnica decisória da hermenêutica dos precedentes judiciais, também, precisa ser efetivamente utilizada de forma adequada. Ou seja, a hermenêutica dos precedentes possui uma prerrogativa constitucional, conforme os elementos da própria CRFB/1988 que claramente visam dar uniformidade e estabilidade ao sistema jurídico brasileiro.

Diante dos exemplos trazidos à discussão pode-se verificar que existem inconsistências na aplicação das duas técnicas no que tange os limites de sua aplicação. Contudo, a aplicação das sentenças normativas é melhor utilizada, já em relação ao respeito dos próprios precedentes pelas cortes, o estudo revelou que os tribunais não aplicam tal técnica com o devido rigor criteriológico, e por isso as incongruências são ainda maiores.

Finalmente, reputa-se possível a possibilidade de se extrair, a partir do exposto sobre as formas de controle da liberdade interpretativa exercida pelos tribunais, uma possibilidade das cortes superiores seguirem seus precedentes como forma de equiparar forças expansivas advindas do uso das sentenças normativas e garantir a manutenção, a evolução e a continuidade do direito. Entretanto, é preciso ressaltar que ambas técnicas precisam de critérios de utilização, e que tais critérios devem ser seguidos.

\section{REFERÊNCIAS BIBLIOGRÁFICAS}

ALEXY, Robert. 2002. Teoria de los Derechos Fundamentales. Madri: Centro de estudos políticos e constitucionales, 2002. 
BARROSO, Luís Roberto. Curso de direito constitucional comptemporâne: os conceitos fundamentais e a construção de um novo modelo. 2. ed. São Paulo: Saraiva 2010.

BRASIL. Constituição (1988). Constituição da República Federativa do Brasil: versão atualizada até a Emenda n. 88/2015. 46. ed. (Coordenação de Edições Técnicas)

BRASIL. Constituição anteriores. Legislação histórica Disponível em: <http://www4.planalto.gov.br/legislacao/legislacao-historica/constituicoesanteriores-1>. Acesso em: 29 nov. 2016.

BRASIL. Lei $\mathrm{n}^{\mathbf{0}} 13.105,16$ mar. 2015. Código de processo civil e normas correlatas [livro eletrônico]. Brasília, DF. : Senado Federal, 2015. (Coordenação de Edições Técnicas).

BRASIL, Superior Tribunal de Justiça. Acórdão. Recurso Especial $\mathbf{n}^{\mathbf{0}}$ 1.558.086/SP. $2^{\mathbf{o}}$ Turma. Rel. Min. Humberto Martins. Direito Público. Publicidade de alimentos dirigida à criança. Abusividade e venda casada. Julgado em 02 de junho de $2016 . \quad$ Disponível em: $<$ https://ww2.stj.jus.br/processo/pesquisa/?aplicacao=processos.ea\&tipoPesquisa $=\mathrm{ti}$ poPesquisaGenerica\&termo=REsp\%201558086> Acesso em 28 abr. 2017.

BRASIL, Supremo Tribunal Federal. Acórdão. Habeas Corpus $\mathbf{n}^{\mathbf{0}}$ 126.292/SP. Plenário. Rel. Min. Teori Zavascki. Execução provisória após sentença de segundo grau de jurisdição. Julg. Em 02 set. 2016. Disponível em: <http://redir.stf.jus.br/paginadorpub/paginador.jsp?docTP=TP\&docID=10964246> Acesso em 28 abrl. 2017.

BRASIL, Supremo Tribunal Federal. Acórdão. Habeas Corpus $\mathbf{n}^{\mathbf{0}}$ 135.100/mg. Tutela antecipada. Decisão monocrática. Min. Celso de Mello. Execução provisória após sentença de segundo grau de jurisdição. Julg. Em 01 jun. 2016. Disponível em: <http://s.conjur.com.br/dl/presuncao-inocencia-prisao-segundograu.pdf> Acesso em 28 abrl. 2017.

BRASIL, Supremo Tribunal Federal. Acórdão. Habeas Corpus $\mathbf{n}^{\mathbf{0}}$ 84.078/SP. Julgamento monocrático. Rel. Min. Eros Grau. Presunção de inocência e execução antencipada. Julg. Em 05 fev. 2009. Disponível em: <http://www.sbdp.org.br/arquivos/material/1958_23_bas_hc84078_ementa_acordao _relatorio_extrato.pdf> Acesso em 28 abrl. 2017. 
BRASIL, Supremo Tribunal Federal. Acórdão. Habeas Corpus preventivo $\mathbf{n}^{\mathbf{0}}$ 140.213/SP. Julgamento monocrático. Rel. Min. Luiz Fux. Execução provisória após sentença de segundo grau. Julg. Em 15 mar. 2017. Disponível em: <http://s.conjur.com.br/dl/fux-permite-prisao-juiz-condenado.pdf > Acesso em 28 abrl. 2017.

BRASIL, Supremo Tribunal Federal. Acórdão. Recurso Extraordinário $\mathbf{n}^{\mathbf{0}}$ 641.320/RS. Plenário. Rel. Min. Gilmar Mendes Cumprimento de pena em regime menos gravoso ante a falta de vagas em estabelecimento penitenciário adequado. julgado em 11 de maio de 2016, Repercussão Geral. Diário Oficial da República Federativa do Brasil. Brasília DF, maio de 2016. Disponível em: $<$ http://stf.jus.br/portal/processo/verProcessoAndamento.asp?incidente=4076171 > Acesso em 28 abr. 2017

CALAMANDREI, Piero. De las buenas relaciones entre los jueces y los abogados en el nuevo proceso civil: dos dialogos / Piero Calamandrei; traducción de Santiago Sentis Melendo. 3. ed. Buenos Aires : Depalma, 1990.

CANARIS, Claus-Wilhelm. Pensamento sistemático e conceito de sistema na ciência do direito. Introdução e Tradução: Antônio Menezes Cordeiro. Lisboa: Fundação Calouste Gulbenkian, 1989.

CARVALHO NETTO, Menelick de; SCOTTI, Guilherme. Os direitos fundamentais e a (in)certeza do direito: a produtividade das tensões principiológicas e a superação do sitema de regras. 1. ed. Belo Horizonte: Editora Fórum, 2012.

CONTINENTINO, Marcelo Casseb. História do Controle de Constitucionalidade das Leis no Brasil. 1. ed. São Paulo: Almedina, 2015.

COSTA, Miguel do Nascimento. Direito Fundamental à Resposta Correta e Adequada à Constituição. Constituição Economia e Desenvolvimento: Revista Eletrônica da Academia Brasileira de Direito Constitucional, Curitiba, v. 5, n. 8, p.170-189, 2013. Disponível em: 〈http://abdconst.com.br/revista9/revista8.pdf> Acesso em 18 abr. 2017

COUTURE, Eduardo Juan. Fundamentos do direito processual civil. Trad. de Rubens Gomes de Sousa. São Paulo: Saraiva, 1946.

DWORKIN, Ronald. Levando os direitos a sério. Trad. Nelson Boeira. 1. ed. São Paulo: Martins Fontes, 2002. 
DWORKIN, Ronald. Uma questão de princípios. Trad. Luis Carlos Borges. 2. ed. São Paulo: Martins Fontes, 2001.

FERRAZ JR, Tercio Sampaio. Introdução ao estudo do direito: técnica, decisão, dominação. 9. ed. São Paulo: Atlas, 2016.

FERREIRA, Fábio Luiz Bragança. Decisão judicial e políticas públicas: o juiz, a lei e o termômetro. Constituição Economia e Desenvolvimento: Revista Eletrônica da Academia Brasileira de Direito Constitucional, Curitba, v. 7, n. 13, jul-dez, p. 476495, 2015. Disponível em: <http://abdconst.com.br/revista14/revista13.pdf> Acesso em 18 abr. 2017

HABERMAS, Jurgen. A inclusão do outro. Trad. George Speber e Paulo Astor Soethe. São Paulo: Loylola, 2002.

LARENZ, Karl. Derecho justo - fundamentos de la ética jurídica. Tradução de Luiz Diez-Picazo. Madrid: Civitas, 1985.

LORENZETTI, Ricardo Luis. Teoria da decisão judicial: fundamentos de direito. Trad. Bruno Miragem. São Paulo: Revista dos Tribunais, 2009.

MARINONI, Luiz Guilherme. Precedentes Obrigatórios. 4. ed. rev. e ampl. São Paulo: Editora Revista dos Tribunais, 2016.

MARINONI, Luiz Guilherme. Teoria Geral do Processo - Curso de Processo Civil Volume 1. 3. ed. rev. e ampl. São Paulo: Editora Revista dos Tribunais, 2008.

MÜLLER, Friedrich. Métodos de Trabalho de Direito Constitucional. 3. ed., Rio de Janeiro: Renovar, 2005

ABBOUD, Geores. NERY JUNIOR, Nelson. Stare decisis VS. Direito Jurisprudencial. In: FREIRE, Alexandre. Dantas, Bruno. NUNES, Dierle. DIDIER JR., Fredie. MEDINA, José Miguel Garcia. FUX, Luís. CAMARGO, Luís Henrique Volpe. OLIVEIRA, Pedro Miranda de. (Org.). Novas tendências do Processo Civil. Estudos sobre o Projeto do Novo Código de Processo Civil. Salvador: Jus Podivm, 2013.

OLIVEIRA, Ana Carolina Borges de. Diferenças e Semelhanças Entre os Sistemas da Civil Law e da Common Law. Constituição, Economia e Desenvolvimento: Revista Eletrônica da Academia Brasileira de Direito Constitucional, Curitiba, v. 6, n. $10, \quad$ p. 43-68, jun. 2014. Disponível em: <http://abdconst.com.br/revista11/revista10.pdf> Acesso em 18 abr. 2017 
PULIDO, Carlos Bernal. O Direito dos direitos - Um Escrito Sobre a Aplicação dos Direitos Fundamentais. Tradução de Thomas da Rosa de Bustamante. São Paulo: Marcial Pons, 2013.

PERELMAN, Chain; OLBRECHTS-TYTECA, Lucie. Tratado da argumentação: a nova retórica. Trad. Maria Galvão. São Paulo: Wmf Martins Fontes, 2005.

SARLET, Ingo Wolfgang. A Eficácia dos Direitos Fundamentais. Uma teoria geral dos direitos fundamentais na perspectiva constitucional. Porto Alegre: Livraria do Advogado, 2010.

SOUSA FILHO, Ademar Borges de. Sentenças Aditivas na jurisdição constitucional brasileira. Belo Horizonte: Fórum, 2016.

STRECK, Lenio Luiz. Jurisdição Constitucional e Decisão Jurídica. 4. ed. São Paulo: Revista dos Tribunais 2014.

STRECK, Lenio Luiz. O que é isto - o precedente judicial e as súmulas vinculantes. 4. ed. São Paulo: Livraria do Advogado, 2016.

TUCCI, José Rogério Cruz e. Precedente judicial como fonte do direito. São Paulo: Revista dos Tribunais, 2004.

ZANETI, Hermes Jr. A constitucionalização do processo. 2. ed. São Paulo: Atlas, 2014.

ZANETI, Hermes Jr. O Valor Vinculante dos Precedentes. 1. ed. São Paulo: Editora Jus Podivm, 2015.

Data da submissão: 30/04/2017 Data da primeira avaliação: 17/07/2019 Data da segunda avaliação: 12/09/2019

Data da aprovação: 12/09/2019 